\title{
Estrategias de dominación editorial: la exportación del libro infantil y juvenil español en América Latina (1977-2017)
}

DELIA GUIJARRO ARRIBAS CESSP/EHESS, Francia / delia.guijarro@gmail.com

\section{Resumen}

Este artículo examina el proceso de implantación de las editoriales españolas en los mercados del libro de América Latina. A través del foco de los libros de literatura infantil y juvenil el artículo analiza las estrategias puestas en marcha para imponer una dominación editorial y literaria en el área lingüística hispanohablante.

Palabras clave: libro infantil y juvenil / editores /

España / América latina / espacio lingüístico

\section{Publishing strategies domination: export of the Spanish children's books in Latin America (1977-2017) \\ Abstract}

This article examines the process of implementing Spanish publishers in Latin American book markets. Through the focus of children's literature books, the paper analyzes the strategies put in place to impose a publishing and literary domination in the spanishspeaking linguistic areas.

Key words: children's books / publishers / Spain / Latin American / linguistic areas

Recibido: 9/12/2019. Aceptado: 4/3/2020

Para citar este artículo: Guijarro Arribas, D. (2020). Estrategias de dominación editorial: la exportación del libro infantil y juvenil español en América Latina (1977-2017). El taco en la brea, 11 (diciembre-mayo), 20-30. Santa Fe, Argentina: UNL. DOI: 10.14409/tb.v1i11.9151 
Hemos leído: el futuro de España está en América. De Latinoamérica nos llega mucho impulso, mucha juventud, muchos valores. Y, aunque sólo fuera por la cantidad de niñas y niños que viven en aquel inmenso continente, también podemos decir que el futuro de nuestra literatura infantil y juvenil (contenido y negocio) está cada día un poco más de la parte de allá. (Cortés Salinas:6)

Así se expresaba en 2010, José Luis Cortés Salinas, presidente de la Fundación SM, propietaria de las Ediciones SM, uno de los líderes del mercado de publicaciones escolares y de literatura infantil y juvenil en español. Su testimonio es una muestra más de la importancia que los editores españoles de libros infantiles y juveniles otorgan a los diferentes mercados de América Latina.

Estudiar la circulación internacional de los libros infantiles y juveniles permite dar cuenta de los mecanismos y las lógicas propias al mercado de la edición. El mercado mundial de los libros destinados a la infancia se encuentra encastrado en el mercado mundial de la edición. Desde los años noventa, este último ha sido estudiado por los sociólogos de la cultura (Heilbron y Sapiro, 2002a y b), que han combinado el marco teórico de los campos de Pierre Bourdieu (Bourdieu), con el de centro-periferia propuesto por Abram de Swaan para analizar las lenguas (De Swaan). En la introducción del libro Translatio, Gisèle Sapiro enuncia además la formación de espacios editoriales transnacionales en distintas áreas lingüísticas a través de la circulación de los libros en lengua original (Sapiro, 2008).

Siguiendo este marco teórico y metodológico, el presente artículo pretende examinar las estrategias desarrolladas a partir de los años setenta por cinco grandes editores españoles de literatura infantil y juvenil (SM, Edebé, Edelvives, Santillana y Anaya) para exportar su producción a través, no de la venta de derechos de traducción, pero de la distribución directa de los libros en lengua original en un área lingüística compartida. Nos situamos así al nivel del subcampo editorial infantil y juvenil de España y de sus relaciones transnacionales dentro del área lingüística hispanohablante (veremos también, aunque en menor medida, las relaciones con el espacio de habla portuguesa). En primer lugar, explicaremos cómo el Estado español impulsó de manera institucional la instalación de las editoriales españolas en América Latina. En segundo lugar, nos interesaremos en las prácticas económicas y culturales desarrolladas por estos grandes grupos para mantenerse de manera duradera en los diferentes países. Por último, proponemos comparar la expansión de los editores españoles de literatura infantil y juvenil en los países hispanohablantes con la expansión de los editores franceses en los países francófonos, para dar cuenta del peso de las áreas lingüísticas en la formación de espacios de edición transnacionales y las particularidades que les caracterizan respectivamente.

\section{Una estrategia de expansión enmarcada por el Estado}

El mercado mundial de la edición se estructura gracias a los Estados-nación y a las áreas lingüísticas (Sapiro, 2009:276). Las producciones literarias de las áreas lingüísticas están controladas y polarizadas por uno o varios centros. España y concretamente Madrid dominan en el caso de la edición infantil y juvenil hispanohablante. En este espacio es innegable que se comparte la misma lengua, e incluso una parte del panteón literario. Por ejemplo, cuando se pregunta a los alumnos de Puerto Rico sobre los clásicos de literatura que leen, estos citan como prioridad: Don Quijote de la Mancha de Miguel de Cervantes, el Cantar de mío Cid o Cien años de soledad de Gabriel García Márquez (Ayes:162). 
Desde 1977, los grandes grupos españoles de edición escolar y de literatura infantil y juvenil, la mayoría situados en Madrid, han instaurado filiales de edición por toda América Latina (véase mapa 1). En algunos países de América del sur, como Perú o Ecuador, donde el sector editorial y las prácticas de lecturas son frágiles, las editoriales españolas controlan la mayor parte del mercado nacional (Ediciones SM, 2005). Así mismo, la mayoría de los agentes literarios especializados en los libros infantiles y que trabajan para todo el espacio iberoamericano se sitúan en Madrid o en Barcelona.' Estos agentes representan a los autores españoles y latinoamericanos en la cesión de derechos de autor y de derechos de traducción, así como los catálogos infantiles y juveniles de las editoriales de otros países en este espacio.

¿Por qué y cómo se han instalado estas filiales? Gisèle Sapiro ha demostrado que la conquista de nuevos mercados no es solamente el resultado de una estrategia económica, sino también cultural (2009:278). En 1978, la revista institucional El libro español, publicada por el Instituto Nacional del Libro Español (INLE), justificaba de la siguiente forma la intervención del Estado para garantizar y mejorar la presencia de las empresas editoriales del país en los mercados latinoamericanos del libro:

El análisis profundo de lo que representa la permanencia del libro español en los países iberoamericanos de un modo continuado, no solamente valorando el aspecto económico, muy respetable por sí solo, sino el valor cultural que esta presencia representa para España, debe ser el argumento de partida para que la Administración española conceda un apoyo decidido a la industria cultural. (Duelo Cavero:31)

Este mismo año, el Estado español puso en marcha la llamada misión de los editores en América Central. La misión consistía en un viaje diplomático de trece editores del país a Panamá, Costa Rica, Nicaragua, Guatemala y México, acompañados del director del departamento de gestión del INLE. La diplomacia española residente en estos países fue la encargada de la organización de los encuentros entre dichos editores y los diferentes actores del comercio y de las políticas del libro en estos países. Por un lado, los editores españoles se reunieron con los responsables de las cámaras locales de industria y comercio con el objetivo de renegociar los acuerdos de importación de los libros. Por otro lado, la misión preveía reuniones con los ministros de educación correspondientes para impulsar la posición de las editoriales españolas en cuanto a la producción del libro de texto escolar.

En Panamá, la fabricación de la mayoría de los libros de texto escolar estaba financiada por los fondos estadounidenses AYDE. Pero la utilización de estos fondos dependía del estatuto del país fabricante. La condición impuesta por los Estados Unidos a Panamá para poder acceder a tales fondos consistía en el establecimiento de acuerdos de impresión con editoriales de países clasificados por los Estados Unidos en la categoría de subdesarrollados; con lo cual las editoriales españolas se quedaban fuera del juego. A pesar de las dificultades, la misión de los editores consiguió convencer al ministro de educación de Panamá de la compra a editoriales españolas, con fondos propios del ministerio, de una parte de los libros de texto escolar. Dicha misión resultó aún más ventajosa en el caso de Costa Rica y Guatemala. Además de obtener la edición de los libros de texto para la enseñanza primaria y secundaria, los editores españoles consiguieron participar directamente en la elaboración de los programas escolares (Duelo Cavero:32). Si bien es cierto que dicha misión en América Central permitió establecer un marco económico entre estados soberanos, no hay que obviar que una relación de jerarquía se impuso a favor de España, a la manera de un imperio informal. ${ }^{2}$ 
A través de la revista El libro español, el INLE proporcionó informaciones concretas sobre la situación de cada mercado editorial en América Latina, especificando los acuerdos ya existentes, la situación política, económica o la legislación de cada país. De esta forma, por ejemplo, la revista informó en 1978 acerca de la censura instaurada en Brasil, aplicada en particular a las publicaciones extranjeras. A través de la revista se proporcionaron soluciones para poder adaptarse a esta situación y vender la producción (El libro español, 1978:36). De la misma manera, el INLE aconsejó a los editores españoles de no limitarse a la distribución directa, sino de instaurar sucursales o filiales locales de producción, puesto que este era el único medio, según la institución, que podía garantizar una presencia continua en América Latina. Así el INLE resaltó las numerosas ventajas de tal estrategia: supresión del paso por las aduanas y la conversión de las divisas, reducción de la piratería y del tiempo de espera en los cobros, menor coste de fabricación, acceso a una mano de obra más barata para las correcciones y las relecturas, o incluso una mejor promoción de la marca en el país, en particular respecto de las instituciones locales, como los colegios o las bibliotecas (El libro español, 1978).

Algunas editoriales españolas crearon filiales de producción a finales de los años setenta. En cuanto a la edición escolar y de libros infantiles, Santillana creó en 1977 una filial en Caracas, y otras tres en 1981 en Buenos Aires, Santiago de Chile y Lima (véase mapa 1). Esta estrategia fue adoptada de manera mayoritaria a partir de 1982 tras la crisis económica mexicana. Con el objetivo de reducir la deuda pública, México endureció las condiciones de importación de los libros, obligando a los distribuidores y libreros a obtener permisos de importación y reforzando los controles en los cambios de divisas. La revista El libro español publicó entonces la siguiente frase: «Hoy por hoy es impensable para un distribuidor o librero local pensar en términos de importación del libro español como antes de 1982» (El libro español, 1984:66). Para hacer frente a los obstáculos impuestos por el gobierno mexicano, las grandes editoriales españolas se inclinaron por la compra de editoriales locales o por la instalación de sus propias filiales locales de producción, como fue el caso de las editoriales católicas Edebé, Edelvives y SM. Una vez asentadas en cuanto al mercado del libro escolar, las grandes editoriales españolas comenzaron en cuestión de meses a desarrollar el sector de los libros de literatura infantil y juvenil.

\section{Una estrategia entre la dominación y la adaptación}

Una de las características principales del mercado editorial infantil y juvenil es su dependencia, más o menos importante, respecto de las políticas culturales y educativas de los Estados, dado que tanto las bibliotecas públicas como los centros escolares son a menudo los principales compradores. En buena parte de los Estados de América Latina, como es el caso de Brasil, Argentina, Colombia, Ecuador, El Salvador, Venezuela o México, esta dependencia es aún mayor, puesto que existen programas públicos de compra de libros de literatura infantil y juvenil (Ediciones SM, 2005). Para poder participar a estas licitaciones públicas es obligatorio que la editorial esté registrada como nacional, por lo que las filiales locales cumplen un papel decisivo, creando importantes oportunidades de desarrollo para las grandes editoriales que disponen de una fuerte capacidad de producción. En el caso de Colombia, la filial de la editorial SM ha conseguido hacerse con la primera plaza en cuanto a las compras realizadas por los centros escolares y culturales públicos a través del programa Vitrinas Pedagógicas. En 2006, año de instalación de SM en Colombia, fueron comprados 250 títulos de la popular colección El Barco de Vapor (Ramírez:132). 
Pero para mantenerse de forma duradera en los mercados latinoamericanos del libro infantil y juvenil fue necesario convencer también de manera individual a los prescriptores de libros de literatura (bibliotecarios, profesores o críticos literarios). Para ello, la realización de catálogos propios fue una de las estrategias principales puestas en marcha por parte de las filiales locales de los grupos de edición españoles. Práctica que ha ido desarrollándose a lo largo de los años. El análisis de estos catálogos muestra que están compuestos casi exclusivamente de autores nacionales. De los 266 libros que aparecen en el catálogo publicado en 2017 por la filial argentina de SM, 241 están realizados por autores argentinos, 16 por españoles, 7 por uruguayos y 2 por peruanos. De la misma forma, todos los autores que componen el catálogo de la filial argentina de Santillana (llamada Loqueleo) para el año 2017 son argentinos. Enrique Pérez Díaz, presidente desde 1993 a 2008 de la sección de literatura infantil y juvenil de la Unión de Escritores y Artistas de Cuba (UNEAC) y miembro del comité cubano del International Board on Books for Young People (IBBY), ${ }^{3}$ dijo respecto de esta estrategia:

El paulatino establecimiento de grandes grupos editoriales españoles como Grupo SM, Anaya, Edebé, Santillana, etc., a lo largo de América Latina se ha realizado de manera sistemática y estudiada. Difundiendo por una parte en cada país lo más granado del catálogo general de la colección y de la otra tratando de potenciar nacionalmente en cada sitio un staff de autores que, sin dejar de adecuarse a las premisas de este catálogo, de alguna forma representen lo más genuino de la literatura infantil nacional. (108)

Además, estos catálogos se adaptan a las conmemoraciones nacionales o ponen de relieve los autores nacionales consagrados; como ejemplo pueden verse los numerosos títulos que se publicaron en cada país para la celebración de los bicentenarios de las independencias, o la publicación por parte de la filial de SM en Perú de una serie de libros en torno a la figura del célebre escritor Alfredo Bryce Echenique, llamada ¡Bryce en el cole!, comercializada exclusivamente en este país.

En efecto, pese a compartir una misma lengua y a la presencia de ciertos grupos editoriales en el conjunto del área lingüística, los libros infantiles circulan poco entre los diferentes países de América Latina. Una de las razones que lo explica es la imposición de techos de venta a las filiales por parte de las editoriales españolas (editoriales madre). Se trata del establecimiento de un mínimo de ejemplares que las filiales deben haber vendido para que los títulos publicados sean distribuidos fuera de las fronteras nacionales. Pocos títulos consiguen alcanzar dichos techos, la cantidad establecida es aún más alta para poder acceder a una distribución en el territorio del Estado español. Sin embargo, los títulos publicados por las editoriales madre en España no están sometidos a tales reglas para ser distribuidos en América Latina. Gisèle Sapiro ha podido observar esta misma práctica respecto de la literatura adulta (2009:278). Las editoriales justifican muchas veces la imposición de estas reglas a través de la cuestión lingüística, otorgando al español de España un valor de lengua neutra o incluso de lengua literaria. Así, los agentes literarios que se dedican a los libros infantiles nos han confirmado la dificultad que tienen para vender los derechos de los autores latinoamericanos fuera de sus fronteras nacionales. María Teresa Andruetto, escritora argentina y ganadora en 2012 del premio Hans-Christian Andersen (considerado el premio Nobel de la literatura infantil y juvenil), puso de relieve la cuestión lingüística en el discurso de recogida de dicho premio: 
Muchas veces me han dicho que mis libros son «demasiado argentinos», mas creo que es justamente ahí, en los matices de la lengua, donde reside el desafío de un escritor, su campo de batalla. Mientras más ahondamos en lo particular, mientras menos estándar es nuestra escritura, más difícil se vuelve su exportación. ${ }^{4}$

Para dominar el mercado del libro infantil y juvenil en América Latina las estrategias de los grupos españoles no se han limitado al establecimiento de filiales y a la adaptación de los catálogos. Para ganarse el favor de los prescriptores y del público, estos grupos han multiplicado las actividades de promoción de sus marcas, mediante la creación de premios literarios y de fundaciones que proporcionan una gran visibilidad. Los premios literarios otorgados por los grupos de edición infantil y juvenil españoles van acompañados de una recompensa monetaria importante y de la garantía de una futura publicación del autor en el catálogo nacional. Muchos de estos premios se otorgan además durante las ferias y salones nacionales del libro infantil y juvenil. La editorial SM ha creado incluso el premio «Iberoamericano de Literatura infantil y juvenil» que recompensa, desde 2005 y durante la Feria del libro de Guadalajara (México), un libro infantil escrito en lengua española o portuguesa. Por otro lado, los grupos católicos en particular han creado fundaciones que financian talleres de escritura y simposios sobre la literatura infantil y juvenil (Muñoz Ledo:179), en sintonía con su misión de enseñanza y sus valores religiosos (recordar aquí que la editorial SM pertenece a la congregación católica de los marianistas, Edelvives a los hermanos maristas y Edebé a los salesianos). En el caso de Colombia, la Fundación SM ha puesto además en marcha un sistema de becas otorgadas a los maestros para viajar a España y participar de los cursos de literatura infantil y juvenil impartidos en la Universidad de Castilla La Mancha (Sánchez Lozano:155). ${ }^{5}$ En efecto, si la lengua es importante para dominar un área lingüística, otros factores culturales también lo son. Una buena parte de estos territorios están unidos por un catolicismo muy influyente desde hace mucho tiempo en los espacios educativos. La presencia histórica de la iglesia católica y de las órdenes de misioneros españoles en América Latina, permiten en parte explicar la rápida integración de las editoriales católicas españolas del otro lado del Atlántico.

Compartir una misma lengua facilita los contactos y el acceso a los mercados, pero no significa que las estrategias de expansión de las editoriales españolas se limiten al espacio hispanohablante, como muestra su presencia en Brasil (Santillana se instaló en 1989, SM en 2004, Edebé en 2013). El caso de Brasil es emblemático en cuanto a los lazos que unen los sectores editoriales de habla española y portuguesa. En este caso la lucha se juega a nivel del control de los contratos de traducción; una gran parte de los derechos de traducción de la literatura infantil y juvenil desde todas las lenguas hacia el portugués/brasileño están gestionados por los agentes literarios de Madrid y de Barcelona. En 2007, esta dominación condujo a la compra por parte de la editorial SM España, y no por la de su filial brasileña, de los derechos de la obra completa de una de las escritoras más prestigiosas de la literatura infantil brasileña y la primera escritora latinoamericana que obtuvo en 1982 el premio Hans-Christian Andersen, Lygia Bojunga Nunes. Desde esta compra, la publicación de la obra de esta escritora depende de la entera voluntad de la editorial española.

No cabe duda de que los grandes grupos españoles de literatura infantil y juvenil llegaron a América Latina a través del sector de la edición escolar. A pesar de que ya poseían amplias redes de distribución, instalaron además filiales locales de edición que les han proporcionado una gran visibilidad y un amplio margen de maniobra. La existencia de estas filiales no significa por tanto que los libros de literatura infantil y juvenil publicados en España por las editoriales madres no estén 
distribuidos en los diferentes países de América Latina. Más bien al contrario, los libros españoles se distribuyen más fácilmente en los mercados latinoamericanos, puesto que las filiales han popularizado la marca tanto de cara al público como de las instituciones locales. La exportación de libros infantiles y juveniles en España representa el 15 \% de las exportaciones totales de todo el sector de la edición. Para el año 2014, según los datos de exportaciones de libros infantiles y juveniles publicados por la Federación del Gremio de Editores de España, calculados según las facturas de los distribuidores y libreros, México con el $30 \%$ y Argentina con el $15 \%$ concentran el $45 \%$ de todas las exportaciones en este sector, seguidos de Portugal, Perú, Chile y Colombia (FGEE, 2015:38).

\section{Editores españoles versus editores franceses: dos estrategias diferenciadas}

Hemos visto hasta aquí cómo los mercados latinoamericanos son fundamentales para los grandes grupos españoles de libros de literatura infantil y juvenil, pero no lo son menos para las pequeñas editoriales. Estas últimas no poseen filiales locales de edición, pero ponen en marcha otros mecanismos que garantizan su plena distribución y el acceso a las licitaciones públicas. Así el director de la editorial valenciana Media Vaca nos contaba en una entrevista:

[En México] lo que tenemos es una editorial socia que tiene problemas para distribuir sus propios libros en el país, pero con ellos nos presentamos a las licitaciones de compra de libros gratuitos por el gobierno. Este programa ha mantenido a muchas editoriales pequeñas, también a las grandes. Pero la SEP (Secretaria de Educación Pública) ha comprado al menos 15 títulos nuestros haciendo tiradas de entre 2000 y 100 ooo ejemplares, dinero que ha venido muy bien a los autores y a nosotros para poder seguir trabajando. A veces es más importante la venta allí que la que hacemos aquí. ${ }^{6}$

De esta forma la editorial local socia se encarga de presentar las propuestas de libros infantiles y juveniles a las licitaciones públicas, lo que permite a la pequeña editorial española acceder a los programas de libros gratuitos del gobierno mexicano. Poner en práctica este mecanismo depende en gran medida de la red personal de la que dispone cada editor. Los pequeños editores que no tienen acceso a esta posibilidad suelen tener distribuidores diferentes en cada país, y para los países en los que las ventas son menos importantes, intentan entrar en contacto directamente con las librerías. Arianna Squilloni, directora de la editorial A Buen Paso, se encuentra en esta situación. Así, esta editora nos aseguraba en una entrevista que, a pesar de las dificultades: «América Latina es una parte muy importante, yo creo que vendo más allí que en España». ${ }^{7}$ Los editores españoles calculan las tiradas teniendo en cuenta la distribución en América Latina. Para la editorial A Buen Paso, de los 2500 ejemplares que imprime en primera edición para los álbumes ilustrados, más de la mitad están destinados a su distribución en América Latina. Algunos de estos mercados, como el mexicano, son tan importantes que determinados libros se realizan pensando directamente en el público de ese país; como es el caso del libro ilustrado No hay tiempo para jugar de Media Vaca, que trata del trabajo infantil en México.

Las entrevistas realizadas a los pequeños editores españoles de libros infantiles y juveniles han mostrado la importancia económica que tiene la distribución en el área hispanohablante, sin embargo, las entrevistas a los pequeños editores franceses no destacan la misma importancia en cuanto al área lingüística francófona. Valérie Cussaguet, directora de la pequeña editorial Les Fourmis Rouges, nos explicaba así las proporciones de ventas y tiradas de sus álbumes: 
Digamos que ahora tengo un álbum que ha sido repartido a 3000 ejemplares, de los cuales 500 han sido enviados a la Suiza romanda y Quebec. No significa que estén vendidos, simplemente los han cogido del stock. Quizás me los van a devolver. Pero el distribuidor ha estimado ese envío a 500. En cuanto al África francófona, supone realmente muy poco, porque el precio no corresponde. ${ }^{8}$

Los grandes grupos franceses como Hachette o Gallimard poseen sus propias filiales de distribución y de difusión para los países de la francofonía. Además, estas filiales realizan la distribución para otras editoriales más pequeñas. Sin embargo, en el caso de los libros infantiles y juveniles, incluso para estos editores, el peso económico de dicha distribución es bastante reducido. Una gran parte de las editoriales francesas independientes utilizan para la distribución los servicios de la sociedad Harmonia Mundi. Esta dispone de un socio en Quebec (Dimedia) y otro en la Suiza romanda (ZOE), pero distribuye directamente en Bélgica. En efecto, para la mayoría de los editores franceses de libros infantiles y juveniles, el mercado belga no es más que una prolongación del mercado francés. Pascal Duran e Yves Winkin han estudiado los lazos singulares que unen la edición belga y francesa. En un artículo de 1999, los autores explican la dependencia del mercado editorial belga respecto de su vecino francés, debido a la escasa presencia histórica de una cultura editorial en Bélgica (Durand y Winkin). A pesar de la temprana especialización de los editores belgas en la impresión de la imagen que permitió el desarrollo de los géneros de la bande dessinée y del libro infantil y juvenil, Pascal Durand y Tanguy Habrand han demostrado que hoy día no existe en la edición belga un subcampo de edición infantil y juvenil autónomo, a tal punto que la prestigiosa editorial belga Casterman pertenece actualmente a la francesa Gallimard (Durand y Habrand).

La presencia de los libros franceses en los mercados francófonos de la Suiza romanda y de Quebec es dominante, pero el poco peso demográfico (8 400 ooo habitantes para Quebec y 2000 ooo para Suiza romanda en 2018), hace que estos mercados estén considerados como secundarios por parte de los editores franceses de libros infantiles y juveniles. La directora de la editorial Les Fourmis Rouges, nos decía al respecto:

He calculado la facturación del año para el caso de Quebec. Tuve una facturación de editor total de 300000 euros, Quebec solo suponía 6000 euros, no es mucho. En ese momento me planteé si no era mejor vender los derechos, es decir, si en lugar de distribuir directamente no me valdría la pena vender los derechos de mis libros a un editor de Quebec. ${ }^{9}$

A causa del elevado precio de los libros infantiles y juveniles franceses, en particular de los álbumes, una gran parte de las editoriales francesas no acceden a los mercados de los países africanos de habla francesa. Solamente los grandes grupos que distribuyen libros de texto escolar, como la editorial Hachette, consiguen introducir una pequeña cantidad de libros de lectura para acompañar el proceso de aprendizaje (Pinhas).

No se trata de menospreciar aquí el peso del área lingüística francófona, y en particular de la presencia francesa en Bélgica. No obstante, este recorrido por los diferentes mercados del área francófona, considerada insuficiente por los editores franceses, explica por qué han privilegiado la exportación de su producción infantil y juvenil hacia otras áreas lingüísticas, apoyándose en la cesión de derechos de traducción y sobre todo en el establecimiento de coediciones (Guijarro Arribas, 2020). El sector infantil y juvenil en Francia ocupa así la primera posición en cuanto a 
la venta de derechos. Estas prácticas contrastan con las de los actores del sector de la edición infantil y juvenil en España. Aunque estos últimos intentan, en particular desde los años 200o, impulsar la cesión de derechos de traducción, no cabe duda de que la exportación directa de la producción hacia los países de habla hispana sigue siendo el objetivo más importante.

\section{Conclusión}

Refiriéndose a los mercados del libro de América Latina, muchos han hablado de una puerta naturalmente abierta para los editores españoles, justificando así la dominación de España en estos mercados a través de una supuesta idea de unidad linguiística y cultural entre países iberoamericanos. El análisis de las diferentes estrategias puestas en marcha por los editores españoles de literatura infantil y juvenil para implantarse de manera duradera en los mercados de América Latina pone de manifiesto que estos han tenido que adaptarse a las legislaciones nacionales y buscar el reconocimiento del público y de las instituciones locales, poniendo en marcha un

Mapa 1. Creación de las filiales de las editoriales españolas de literatura infantil y juvenil en América por fecha de creación (1977-2017). Creación del autor. ${ }^{\circledR}$ Delia Guijarro Arribas 2017.

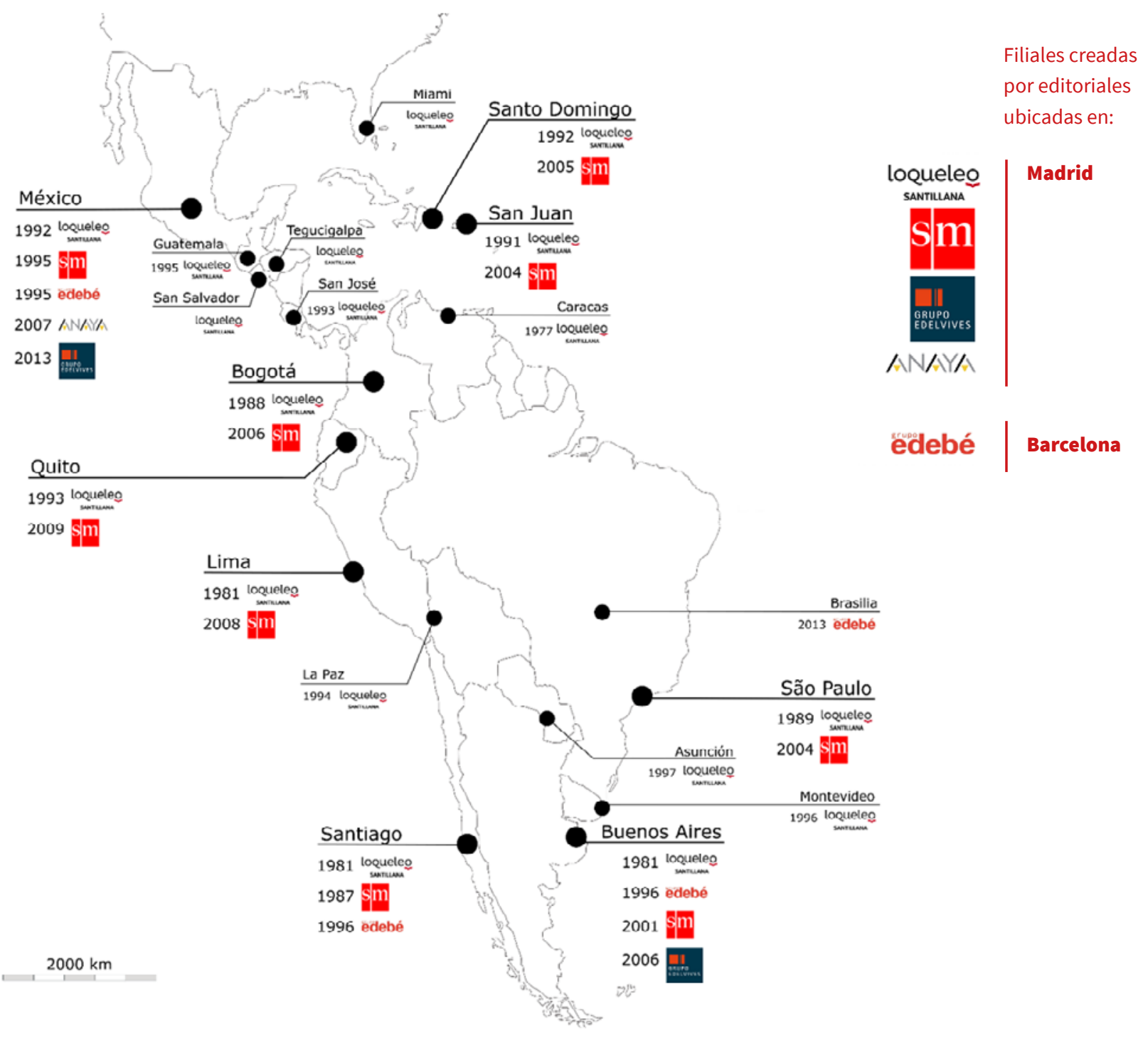


proceso de valorización de la producción local. Este esfuerzo de comprensión y de acomodación no significa por tanto que no haya existido al mismo tiempo una voluntad de dominación y de imposición de sus propias reglas del juego. Tanto los discursos como las prácticas desarrolladas por los actores que han participado en la expansión de la edición infantil y juvenil española en América Latina muestran que el peso demográfico y la estrategia económica han sido y siguen siendo esenciales. Pero son al mismo tiempo la prueba de que lo que está en juego también es una cuestión de dominación cultural y que la imposición no es el único medio para conseguirlo.

\section{Notas}

1 Esta afirmación queda constatada gracias al proyecto de investigación colectivo en curso acerca de los agentes literarios, llevado a cabo en la EHESS y bajo la dirección de Gisèle Sapiro.

$2 \mathrm{El}$ concepto de imperio informal fue teorizado en 1953 por los historiadores británicos John Gallagher y Ronald Robinson en un artículo de 1953 (Robinson:1-15). Este concepto se ha utilizado sobre todo para describir la expansión económica británica y francesa en América Latina a partir del siglo XIX. No obstante, cabe señalar que en el caso de una coerción principalmente económica y diplomática, demostrable en nuestro ejemplo, Michael Mann ha propuesto el concepto de «imperialismo económico» para remarcar la ausencia de intervención militar (Mann:20-39).

3 Principal asociación del subcampo transnacional de la literatura infantil y juvenil creada en 1953. Para profundizar sobre dicha asociación véase Guijarro Arribas (2019).

4 Texto con título La vida misma, leído en Londres el 25 de agosto de 2012.

5 Estos cursos están impartidos por el grupo de investigación CEPLI, creado en la Universidad de Castilla La Mancha, y especializado en el estudio de la literatura infantil y juvenil. Este grupo es uno de los más activos de las universidades españolas en este terreno. Su director Pedro C. Cerrillo Torremocha está además muy integrado a las redes de promoción de la literatura infantil y juvenil en España y en América Latina; ha participado como invitado en numerosas ocasiones en los diferentes salones del libro de literatura infantil y juvenil en Colombia o México, y como jurado en numerosos premios.

6 Entrevista realizada a Vicente Ferrer, codirector de Media Vaca, en Valencia el 13 de julio de 2017.

7 Entrevista realizada a Arianna Squiloni, directora de A Buen Paso, en Barcelona el 24 de noviembre de 2017.

8 Entrevista realizada a Valérie Cussaguet, directora de Les Fourmis Rouges, en París el 25 de octubre de 2018.

9 Entrevista realizada a Valérie Cussaguet en París el 25 de octubre de 2018.

\section{Referencias bibliográficas}

Ayes, Z. (2009). ¿Qué leen los jóvenes puertorriqueños de doce a diecisiete años? Anuario sobre el libro infantil y juvenil. Madrid: Editorial SM, 157-162.

Bourdieu, P. (1984). Questions de sociologie. Paris: Minuit. 113-120.

Cortés Salinas, J-L. (2010). Una crisis para acrisolar. Anuario Iberoamericano. Madrid: Editorial SM, 5-7.

De Swaan, A. (2001). Words of the World: The Global Language System. Cambridge: Polity Press.

Duelo Cavero, C. (1978). La permanencia del libro español en Hispanoamérica. El libro español, (241), 31-35.

Durand, P. y Winkin, Y. (1999). Des éditeurs sans édition [Genèse et structure de l'espace éditorial en Belgique francophone]. Actes de la recherche en sciences sociales, (130), 48-65.

Durand, P. y Habrand, T. (2018). Histoire de l'édition en Belgique XVe-XXIe siècle. Bruxelles: Les Impressions Nouvelles. 
Guijarro Arribas, D. (2019). Du classement au reclassement: Sociologie historique de l'édition jeunesse en France et en Espagne. Tesis de sociología. EHESS.

(2020). Associative practices and translations in children's book publishing: co-editions in France and Spain. En Van Coillie, J. y Mc Martin, J. (Ed.). Children's Literature in Translation: Texts and Contexts. Leuven: Leuven University Press.

Heilbron, J. y Sapiro, G. (Ed.). (2002a). Traduction, les échanges littéraires internationaux. Actes de la recherche en sciences sociales, (14), Paris. https://www.persee.fr/doc/arss_0335-5322_2002_ num_144_1_2803

(2002b). La circulation internationale des idées. Actes de la recherche en sciences sociales, (145), Paris. https://www.persee.fr/issue/arss_0335-5322_2002_num_145_1

Mann, M. (2008). Impérialisme économique et impérialisme militaire américains. Un renforcement mutuel? Actes de la recherche en sciences sociales, 1(171/172), 20-39.

Muñoz Ledo, N. (2009). Actividad editorial en México: mirar el presente, pensar el futuro. Anuario Iberoamericano. Madrid: Ediciones SM, 175-186. https://es.literaturasm.com/anuario-de-literaturainfantil-juvenil

Pérez López, E. (2004). Monográfico: Escribir y leer en iberoamericano. Anuario sobre el libro infantil y juvenil. Madrid: Ediciones SM, 87-126. https://es.literaturasm.com/anuario-de-literatura-infantil-juvenil

Pinhas, L. (2010). Mondialisation, bibliodiversité et littérature de jeunesse francophone. En Foucault, J.; Manson, M. y Pinhas, P. (Eds.). L'Édition de jeunesse francophone face à la mondialisation. Paris: L'Harmattan, 9-21.

Ramírez, C.C. (2007). Lectura y LIJ en Colombia 2006. Anuario sobre el libro infantil y juvenil. Madrid: Ediciones SM, 127-132. https://es.literaturasm.com/anuario-de-literatura-infantil-juvenil

Robinson, R. (1953). The imperialism of free trade. The Economic History Review, 6(1), 1-15.

Sánchez Lozano, C. (2009). Actividad editorial en Colombia. Imágenes y perspectivas. Anuario Iberoamericano, 145-156.

Sapiro, G. (Ed.). (2008). Translatio: Le marché de la traduction en France à l'heure de la mondialisation. Paris: CNRS-Editions.

(2009). Mondialisation et diversité culturelle : les enjeux de la circulation transnationale des livres. En Sapiro, G. (Ed.). Les Contradictions de la globalisation éditoriale. Paris: Nouveau Monde Éditions, 275-301.

\section{Fuentes}

El libro español (1977). Circulación del libro en España e Hispanoamérica. El libro español, (232), 154-157.

(1978). Brasil: censura previa para las publicaciones extranjeras. El libro español, (241), 36.

(1984). Presencia o ausencia del libro español en México. El libro español, (308), 66.

(1984). La libre circulación del libro en América Latina: una estrategia para afrontar la crisis. El libro español, (308), 36-37.

Ediciones SM (2005). Cifras y estadísticas: literatura infantil y juvenil en movimiento. Anuario sobre el libro infantil y juvenil, 9-23.

FGEE (2015). Comercio exterior del libro 2014. Federación del Gremio de Editores de España, 1-156. 